\title{
A SPECULATION ON THE POTENTIAL SUPPORT OF BIO- INSPIRED DESIGN TO BIOLOGICALISATION IN MANUFACTURING
}

\author{
Hashemi Farzaneh, Helena (1); \\ Borgianni, Yuri (2); \\ Forti, David (2); \\ Rauch, Erwin (2) \\ 1: GE Additive, Munich, Germany; \\ 2: Free University of Bolzano-Bozen, Bolzano, Italy
}

\begin{abstract}
The paper investigates to what extent the knowledge accumulated in the field of Bio-Inspired Design might benefit the process of biologicalisation in manufacturing. According to visions making inroads in the manufacturing field, the latter will not be limited to the consideration and the analysis of biological principles as a source of inspiration for solving technical and organizational problems. In fact, the process of biologicalisation in manufacturing foresees the development of bio-integrated and bio-intelligent systems. In light of these expected developments, Bio-Inspired Design's might fail to support the whole transition to take place in the manufacturing field. Methodological limitations still to overcome represent an important barrier in this perspective too. While a transfer of knowledge from the design to the manufacturing domain seems unlikely, the authors individuate aspects that encourage cross-fertilization between Bio-Inspired Design and biologicalisation in manufacturing. These include the need to include biologists in engineering teams, the objective of sustainable development, and a shared attention to the evolution of (Design for) Additive Manufacturing.
\end{abstract}

Keywords: Bio-inspired design / biomimetics, Industry 4.0, Additive Manufacturing, biologicalisation, Multi- / Cross- / Trans-disciplinary processes

\section{Contact:}

Borgianni, Yuri

Free University of Bolzano-Bozen

Faculty of Science and Technology

Italy

yuri.borgianni@unibz.it 


\section{INTRODUCTION}

The fast and constant progress in the fields of biology and information technology over the past few years enabled scientists to observe, understand and simulate complex processes in nature right down to the molecular level and adapt them for human technology. In this context, the biological transformation of the manufacturing processes, machine tools, robots, assembly systems, and sensors has the potential to radically transform the whole manufacturing industry (Miehe et al., 2020). In order to describe the process of convergence of traditional manufacturing towards biological processes, the term biologicalisation has been introduced recently (Byrne et al., 2018). The application of the knowledge derived from the biological principles, processes and resources of nature to industrial manufacturing processes can be also referred to as biological transformation of manufacturing systems (Neugebauer et al., 2019).

The manufacturing domain is therefore paying increasing attention to biologic systems in its evolution, as it will become apparent in Section 2. Undoubtedly, the design world has moved earlier towards the integration of biology knowledge to develop new products and process. In this respect, years of research in bio-inspired design (BID) can be considered as enabler of the evolution of the manufacturing and production systems towards the exploitation of biologic principles, as better justified below.

BID is a well-known field with ramifications in analogical thinking (Fu et al., 2014; Yargin et al., 2018), creative design (Weidner et al., 2018) and problem solving, especially in relation to TRIZ (Baldussu and Cascini, 2015). Other terms are diffusedly used to indicate the concept of BID, such as biomimicry and biomimetics (Fayemi et al., 2017), but the differences between these concepts are subtle and all of them can be used as synonyms in the design field, as they all mirror the definition introduced by the German standard VDI 6620 (2012). Here and in the followings, BID will be consistently intended as the application of knowledge of biological systems in research and development for technical inventions and innovations.

Domke and Hashemi Farzaneh (2018) highlight how developments in robotics and Industry 4.0 have pushed the use of specific classes of bio-inspirations, namely mammals and insects, which has resulted in the superseding of the prevalence of inspirations from the vegetal kingdom. If the main fields of application for BID are taken into account according to Sharma and Sarkar's (2019) analysis, at least three of them can be ascribable to functions useful to the manufacturing domain, i.e. robotics, materials and sensors. Recent cases in point of BID application include composite and other architected materials in (Voelkel and Wartzack, 2018; Jia and Wang, 2019), as well as parts of robots (Li et al., 2019) and machining units (Willocx et al., 2020). Moreover, the implementation of BID principles is extended to the organization of production systems, as in (Dias-Ferreira et al., 2018).

This body of evidence contributes to shape the authors' view that the manufacturing industry can represent a target recipient of BID endeavours. However, the question of how BID can effectively support biologicalisation in manufacturing has not been approached so far. As a first attempt towards this scope, the paper's objective is to infer the possible contribution of available BID methods to develop future manufacturing systems envisaged by biologicalisation in manufacturing.

This objective is pursued by speculating on different facets of the possible BID contribution to biologicalisation in manufacturing. First, the current level of maturity of BID and the design stages it supports are put into relation with the potential needs of biologicalisation in manufacturing, which leads to infer relevant criticalities (Section 3). Second, emerging topics in BID have been gathered by means of a review of recent literature contributions on BID; some trends have been then established, and the potential effects of these trends on biologicalisation in manufacturing have been extrapolated as well (Section 4). Section 5 concludes the paper and summarizes the main findings.

\section{BIOLOGICAL TRANSFORMATION OF MANUFACTURING: A BACKGROUND}

The underlying concept of "biologicalisation in manufacturing" is not new. Since Ueda's (1992) seminal work, there have been some contributions to the field of "biologicalisation in manufacturing", although this term was not explicitly used. What is remarkable, however, is the acceleration of the diffusion of the concept, which builds on the capabilities available nowadays and in the future through developments made possible by the Fourth Industrial Revolution and Industry 4.0 (Byrne et al., 2018). 
Some aspects of the biological transformation in manufacturing seem to be at the backbone of the next phase of the digitalisation and Industry 4.0, as listed below (Byrne et al., 2018).

- Development of new materials and discoveries in chemistry.

- Development of products by using biomaterials.

- Classical industrial processes being influenced by new bio-inspired industrial processes.

- Potential for the introduction of bio-inspired equipment in manufacturing including robotics, machine tools and measuring equipment.

- New bio-inspired models for production organisation including manufacturing systems and supply chains.

While new scientific achievements can boost the trend of biologicalisation in manufacturing, sustainability might be also addressed in this context (Miehe et al., 2020). In a manufacturing perspective, current modes of production massively hamper the prospects of future generations to sustainably satisfy their material needs. In line with Wegener et al. (2018), the next generation of bioinspired production processes could have self-learning and self-optimisation capabilities utilizing realtime information as biological systems already do. Hybrid processes will be involved and there may be potential for the considerable reduction or even the elimination of progressive wear, e.g. of forming and cutting tools. New bio-inspired materials for workpieces and tooling may emerge. Still according to (Wegener et al., 2018), the processes will be resource- and material- efficient and new surface coatings and treatments for biocompatibility and for enhanced wear resistance may emerge. Markedly, machines are expected to feature a greater degree of bio-intelligence due to the introduction of cognition with controls that are based on the working of the human brain (Wegener et al., 2018).

As the latter transformation can be seen as the most futuristic, but still predictable, achievement, the subsections that follow describe three expected degrees of biology integration into manufacturing.

\subsection{Bio-inspired manufacturing}

The first level, referred to as inspiration level, allows the translation of evolutionary biological phenomena into a technical system (Miehe et al., 2019). As, here, the input domain is represented by the nature and the target domain is technology, affinities with BID can be easily found.

The underlying principle is that, in a biological system, each component has a function offering an elegant and cost-effective design (Cohen and Reich, 2016). The objective of this type of approach is to take inspiration from the characteristics of biological systems and stimulate engineers and technicians in order to transfer these concepts to non-living systems such as machines and tools, rather than replicating or analysing the biological entity itself at the molecular scale (Whitesides, 2015). The same applies to materials, as it is possible to transfer a structural concept from nature into a new material. The process is not complicated, but the analysis and careful observation of the natural system is a necessary prerequisite (Pereira et al., 2015), which might benefit from the knowledge of biologists. The information gained through the analysis of the underlying principles of a natural phenomenon can be the basis for solving a technical or technological problem (Pereira et al., 2015). Possible applications are lightweight designs, optimization algorithms, materials, surfaces, and sensor technologies (Drossel, 2019). Examples of bio-inspired concepts are already known in the technological field, since they have been applied for many years, e.g. swarm/ant algorithms. Other examples of technologies inspired by natural systems or processes are insects' exoskeletons, which have given rise to the development of artificial exoskeletons (Miehe et al., 2018) to support workers during tasks requiring high physical effort. In addition, lightweight structures have taken inspiration from bones structures (Miehe et al., 2018).

These approaches are based on the common assumption that several billion years of evolution led to the design of strategies that are optimal for surviving in a particular environment (Drossel, 2019). In particular, nature has succeeded fulfilling contradictory requirements (Hill, 2005) that feature the technical sphere too, e.g. the lightweight structure of a plant which needs to be able to resist to high stress.

\subsection{Bio-integrated Manufacturing}

While in the short term, inspirational aspects will be object of the largest number of studies and practical applications, integrational aspects are expected to dominate future research in the medium term (Miehe et al., 2019). The second level of biological transformation requires the integration of technical and biological processes to combine bio- and traditional manufacturing technology (Miehe et al., 2019). The 
integration of living biological organisms into material networks has predominantly been researched in biomedicine. However, the potential of using organisms as actuators, sensors and controllers for advanced material functions is far from being completed. Ultimately, this can be used to develop 'living materials', i.e. materials that are based on functional, learning organisms (Miehe et al., 2019).

The functionalization of polymers, the recovery of bioplastics from carbon dioxide waste streams, the extraction of methane from industrial wastewater, and the implementation of natural filter mechanisms for closing value creation cycles range among the possible examples. The cooperation mode creates bio-technical systems. The principle of symbiosis is an evolutionary key principle of nature, which is likely to gain relevance in the context of a sustainable industrial value creation (Miehe et al., 2018).

\subsection{Bio-intelligent manufacturing}

The interaction-level represents the final state of the biological transformation of manufacturing, where technological, biological and information systems interact leading to the creation of a selfsufficient, autonomous system (Miehe et al., 2019). A modern system needs to be capable of learning from uncertain and probabilistic data (Wegener et al., 2018).

On the long term, manufacturing systems are required to enable the interaction between all their biological and technical components leading to the development of bio-intelligent value creation (Miehe et al., 2019). The final - and most likely to be a game-changing approach - to future manufacturing science is the complete merging of the bio- and techno-sphere in the form of a thorough cross-linking of biology, manufacturing, and information technology referred to as evolvement (Miehe et al., 2019). Whereas at the bio-integration stage the biological and the technical systems operate independently, at the bio-intelligent level the systems communicate with each other aiming at sustaining the function of the overall systems in the most efficient and sustainable way.

One of the key concepts applying to both biological and technical systems is autonomy. The response of biological systems is heavily related to the interaction between different autonomous entities (DiasFerreira et al., 2018). A manufacturing system is considered bio-intelligent if at least one biological component is present in the product itself or in the manufacturing process, and communicates with the technical parts and/or components (Miehe et al., 2018). Formally, a system can be termed "biointelligent" if it has been designed following some fundamental principles found in nature, it uses biological resources, and it is able to produce locally and autonomously. In addition, the system needs to have an exchange of information between the technical and biological system (Miehe et al., 2019). Machine intelligence is becoming the basis for executing manufacturing processes (Wegener et al., 2018). One of the key challenges of the next few years will be to develop interfaces between the biological and the technical component, enabling the real-time communication between the two subsystems. Miehe et al. (2019) identified the realization of bidirectional, real-time informative connections between technical and biological systems as one of ten critical fields of future research in order to enable bio-intelligent value creation.

\section{MATURITY OF BIO-INSPIRED DESIGN-RELATED METHODS FOR THE MANUFACTURING SECTOR}

BID incorporates a wide range of activities ranging from planning of a BID project to transferring an analogy, i.e. from the biological to the technical domain.

The formulation of these activities slightly differs among researchers, e.g. Lenau et al. (2010) name problem (definition), search, analysis, principle (extraction) and design; the VDI 6620 (2012) guideline additionally includes experiments and testing. Despite these small differences, the general outline of activities is similar. They can be grouped into the following headlines (Hashemi Farzaneh and Lindemann 2019).

- Planning: Depending on the extent of collaboration or integration of biology and technology, a BID project has to take into account the discipline-specific approaches and has to be planned accordingly.

- Abstraction: Abstraction is a recurring element of BID - both the biological inspiration and the technical application have to be formulated in a more or less abstract manner so that a common denominator is reached. This is a basic requirement for analogical transfer. 
- Search: Whenever a BID project originates from a purely biological or a purely technical viewpoint, inspirations have to be found in the other domain. Typically, engineers search for biological inspirations to solve a technical problem.

- Analysis and Comparison: Biological and technical systems have to be analysed carefully and they have to be compared to evaluate the suitability of a biological inspiration for a technical application.

- Transfer: The ultimate goal of BID is to transfer a biological inspiration - which can be more or less abstract to the technical domain. This is an analogical transfer.

To support designers, methods have been developed for each of these BID activities. However, according to (Hashemi Farzaneh and Lindemann 2019), the analysis and comparison as well as the transfer activities are still insufficiently supported.

The following table addresses the applicability and utility of methods for the biologicalisation of manufacturing and points out if different needs might concern some of its three stages only.

Table 1: Applicability of bio-inspired design methods for the three levels of biologicalisation of manufacturing

\begin{tabular}{|c|c|c|}
\hline Activity & Applicability to bio-X manufacturing & $\begin{array}{l}\text { Illustrative methods } \\
\text { within the given activity }\end{array}$ \\
\hline Planning & $\begin{array}{l}\text { Bio-inspired: existing methods applicable } \\
\text { Bio-integrated and bio-intelligent: existing methods } \\
\text { applicable with focus on collaborative projects. Planning } \\
\text { has to address who will be included in the development } \\
\text { (engineering designers/manufacturing specialists/bio- } \\
\text { chemists) and how these specialists can collaborate. }\end{array}$ & $\begin{array}{l}\text { Technology Pull } \\
\text { Procedure (e.g. Lenau et } \\
\text { al., 2010), Biology Push } \\
\text { Procedure (e.g. Helms et } \\
\text { al., 2009), Procedure for } \\
\text { Collaborative Research } \\
\text { Projects (VDI, 2012) }\end{array}$ \\
\hline Abstraction & $\begin{array}{l}\text { Bio-inspired, bio-integrated, and bio-intelligent: existing } \\
\text { methods applicable } \\
\text { Even if the goal is to use a biological system in a } \\
\text { manufacturing system, an initial abstraction of the goals } \\
\text { and functions of biological and technical systems is needed } \\
\text { in order to match them to each other and find the right } \\
\text { interface. }\end{array}$ & $\begin{array}{l}\text { Biocards (Lenau et al., } \\
\text { 2015), Structure- } \\
\text { Behaviro-Function } \\
\text { Modelling (Goel et al., } \\
\text { 2009) }\end{array}$ \\
\hline Search & $\begin{array}{l}\text { Bio-inspired, bio-integrated, and bio-intelligent: existing } \\
\text { methods applicable } \\
\text { Well-established approaches from bio-inspired design can } \\
\text { be used to find suitable biological and technical systems } \\
\text { for all levels of biologicalisation of manufacturing }\end{array}$ & $\begin{array}{l}\text { Catalogs/ Databases of } \\
\text { Biological Principles } \\
\text { (e.g. asknature.org), } \\
\text { BIOscrabble (Kaiser et } \\
\text { al., 2014) }\end{array}$ \\
\hline $\begin{array}{l}\text { Analysis } \\
\text { and } \\
\text { Comparison }\end{array}$ & $\begin{array}{l}\text { Bio-inspired, bio-integrated, and bio-intelligent: existing } \\
\text { methods not sufficient } \\
\text { Methods either address very specific applications (e.g. } \\
\text { material analysis) or remain rather superficial. New } \\
\text { methods have to be developed which are tailored to } \\
\text { - Manufacturing systems } \\
\text { - Bio-integrated and bio-intelligent systems } \\
\end{array}$ & $\begin{array}{l}\text { Four Box Method (Yen } \\
\text { et al., 2014) }\end{array}$ \\
\hline Transfer & $\begin{array}{l}\text { Bio-inspired: existing methods applicable } \\
\text { Bio-integrated and bio-intelligent: existing methods not } \\
\text { applicable } \\
\text { In bio-inspired design, "transfer" covers only the transfer } \\
\text { of abstract analogies. As bio-integrated and bio-intelligent } \\
\text { manufacturing system implies a direct use of biological } \\
\text { systems in the manufacturing process; this activity has to } \\
\text { be extended to "transfer and application". }\end{array}$ & $\begin{array}{l}\text { Formulation of different } \\
\text { analogy types (e.g. } \\
\text { Sartori et al., 2010), } \\
\text { BioId (Hashemi } \\
\text { Farzaneh and } \\
\text { Lindemann, 2018) }\end{array}$ \\
\hline
\end{tabular}

The analysis leads to some open issues, which are reported in the text in italics. As the table shows, the main development gap exists for methods that support the analysis and comparison of biological and technical systems, as well as the transfer of analogies or the application of biological systems in a 
manufacturing system. In particular, these activities are key to deciding on the most suitable level of biologicalisation of manufacturing: Can a manufacturing system perform best as a bio-inspired, biointegrated or bio-intelligent system? And which are the interfaces between biological and technical elements of the manufacturing system?

The overall analysis is graphically illustrated in Figure 1, which intends to summarize the three stages of biologicalisation in manufacturing and BID's major shortcomings in supporting this process.
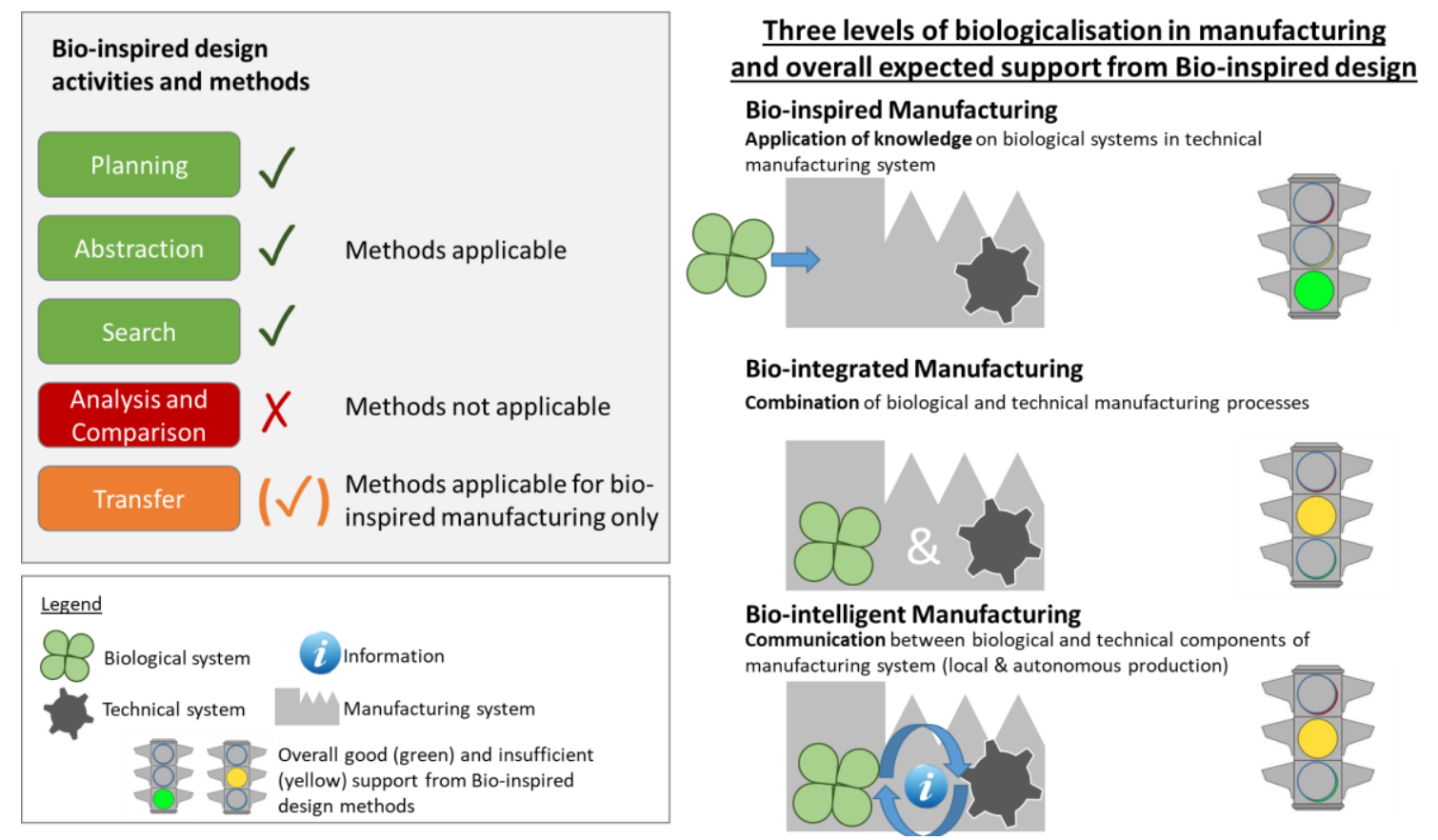

Figure 1: Expectedly mature (green), partly applicable (orange) and not applicable (red) bioinspired design activities and methods to support the three levels of biologicalisation in manufacturing; indication of expected overall support

\section{OPEN ISSUES IN BIO-INSPIRED DESIGN AND IMPLICATIONS FOR MANUFACTURING}

The previous section has highlighted that methodological downsides of BID techniques might hinder its potential support to biologicalisation of manufacturing. In the present section, based on their best knowledge of the topic and a literature search for recent contributions in the BID domain, the authors have tried to capture other aspects that might be relevant to understand how BID should be developed to support biologicalisation in manufacturing. All these aspects are focused on in the subsections that follow, which include a final statement (in italics), which summarizes the authors' stance.

\subsection{BID criticalities for industrial product development processes}

Despite the examples of BID application recalled in Section 1, the diffusion of BID is still limited. A possible reason might be hardships to make BID work for industrial projects, as products are often multifunctional while BID addresses a problem at once (Svendsen and Lenau, 2019). The complexity of nowadays' products and systems, which straightforwardly features the manufacturing industry more than product design and B2C fields, represents a clear obstacle for BID diffusion in its current stage of development. This shortcoming is exacerbated by BID's current failure of having established systematic ways of application (Esat and Ahmed-Kristensen, 2018), which might be particularly critical when design processes require iterations and involve large design teams.

BID's capability of addressing the manufacturing industry can represent a litmus test in terms of it moving from a predominantly academic approach to a valuable resource for industrial development.

\subsection{The matching between additive manufacturing and BID}

Additive manufacturing (AM) technologies are well-known for the freedoms enabled at the design level, e.g. (Thompson et al., 2016). However, they show criticalities for certain geometries, e.g. 
overhangs and thin walls, while the need for supports often represents a further issue to be considered. In this respect, typical geometries emerging from BID applications are supposed to be particularly tailored for AM and 3D printing (Hashemi Farzaneh et al., 2019; Zhang et al., 2020). Markedly, du Plessis et al. (2019) point out how bio-inspiration represents a good candidate for unlocking the still untapped AM potential. Specifically, BID is seen as a possible trigger to ease the design of lightweight structures, which is a fundamental prerogative of design for AM (Vaneker et al., 2020). The combination of the ground-breaking possibilities enabled by BID in terms of addressing towards the redefinition of geometries and materials, and the great potential offered by AM is at the backbone of developments in several fields, e.g. soft robotics (Li et al., 2019).

It is also worth noting that AM technologies are readily usable for at least two of the levels of biologicalisation: (topologically) optimized components to be additively manufactured and biointegrated AM systems, e.g. 3D printing of bio-inspired and cell structures (San Ha and Lu, 2020). Analysing and abstracting the procedures that have been applied to develop these manufacturing systems can support the development of general methods for biologicalisation of manufacturing.

The development of methods for the biologicalisation of manufacturing can largely benefit from existing applications of additive manufacturing technologies. In this respect, developments in bio-inspired design for additive manufacturing might well represent an enabler of biologicalisation of manufacturing.

\subsection{Expertise of teams involved in BID}

A recognized shortcoming of BID is that the majority of methods have been developed from a purely technical perspective and without integrating knowledge and approaches from biologists into the development process. In this respect, a considerable number of recent contributions target the role of expertise of designers, technicians and biologists in the successful application of BID (Graeff et al., 2019; Hashemi Farzaneh, 2020; Letard et al., 2020). However, this limitation is partially alleviated in that BID is oriented to acquire biology knowledge without integrating biological elements into designs, differently from e.g., biophilic design (Sayuti and Ahmed-Kristensen, 2020). Likewise, this stronger biological-technical integration is foreseen when it comes to biologicalisation in manufacturing, markedly in terms of what is needed by bio-integrated or bio-intelligent manufacturing systems.

BID has approached the problem of integrating biologists in design teams, although still at an insufficient level. This issue is made more severe if we look at BID's potential support to biologicalisation in manufacturing.

\subsection{BID principles for organizational problems and communities}

BID's scope is no longer limited to the replication of biological principles to perform technical functions. In fact, increasing attention is paid to BID principles for organizational problems and communities, e.g. (Lee and Baek, 2019). This trend exemplifies the appropriateness of some bioinspired principles to tackle problems concerning complex systems where multiple elements interact and communicate, as for example in swarms.

Especially in light of the emergence of bio-intelligent manufacturing systems, an important development of BID is constituted by its capability of working for organizational and management problems.

\subsection{BID to support sustainable development}

A leading idea behind the introduction of BID is the awareness of nature's capability of evolving in a sustainable way. Therefore, it has been assumed that the imitation of nature would have resulted in development of more environmental friendly systems, products and designs. Unsurprisingly, BID is included in typical lists of methods for eco-design and sustainable design in recent contributions, e.g. (Faludi et al., 2019). However, the effective contribution of BID to sustainable design is questioned by some scholars, as Ceschin and Gaziulusoy (2016) have pointed out. Undoubtedly, sustainability represents an issue shared by all scientific domains and manufacturing is of no exception. In particular, the effects on sustainability brought on by Industry 4.0 are focused on in many recent contributions, e.g. (Bai et al., 2020; Machado et al., 2020), and, as mentioned, it represents a prerogative of biologicalisation in manufacturing.

The full demonstration of BID's capability of supporting sustainable development can strengthen its chances of supporting biologicalisation in manufacturing. 


\section{FINAL REMARKS}

The technological progress has proven to trigger the integration of design and manufacturing disciplines, as in case of Design for Additive Manufacturing (Thompson et al., 2016). The expected trend of a major relevance of biological principles in the manufacturing domain might well represent an additional example where cross-fertilization between design and manufacturing knowledge takes place.

This aspect is investigated in the paper from different points of view. The authors describe below their understanding based on designated trends of biologicalisation in manufacturing, and their knowledge of BID supported by the analysis of recent literature, which has been used to identify the hottest topics in BID. Although these conclusions emerge from a subjective analysis and interpretation, which plainly represents a limitation of the present work, those are reasonable in authors' view in virtue of the mentioned attention paid to literature on BID and biologicalisation in manufacturing.

The design field has invested substantially more resources to understand the potential contribution of biological principles for the solution of technical problems. While BID has attracted considerable attention, some shortcomings and the failure to support some critical design phases still limit its diffusion, especially when it comes to industrial applications and complex systems. In this respect, the paper highlights that the current critical issues affecting BID might represent a barrier to guiding biologicalisation in manufacturing. Moreover, BID has been intended as a set of tools supporting design through the comprehension of biological principles in abstract terms, whereas the aim of integrating biological and technical systems was not in its aims. From this point of view, the expected trajectories of the biological transformation of manufacturing, markedly with respect to bio-integrated and bio-intelligent manufacturing, plainly conflict with BID's objectives. Therefore, just the first level of biologicalisation in manufacturing, i.e. bio-inspired manufacturing, might overall benefit from accumulated knowledge within BID. The authors' thought is supported by a number of BID-oriented solutions developed for the manufacturing field.

On the other hand, a number of possible convergences between BID and biologicalisation in manufacturing have been identified. These include the relevance attributed to AM, which besides concurs to the goals of Industry 4.0 along with biologicalisation in manufacturing, the search for a major integration of biologists in design and engineering teams, the need to address organizational issues and sustainability-related problems. Although these areas cannot be considered as domains of knowledge transfer from BID to manufacturing, they represent common targets. Both research on bio-inspired design and on the biologicalisation of manufacturing should focus on jointly advancing in these areas.

\section{REFERENCES}

Bai, C., Dallasega, P., Orzes, G., and Sarkis, J. (2020), "Industry 4.0 technologies assessment: A sustainability perspective", International Journal of Production Economics, pp. 107776. https://doi.org/10.1016/j.ijpe. 2020.107776

Baldussu, A., and Cascini, G. (2015), “About integration opportunities between TRIZ and biomimetics for inventive design”, Procedia Engineering, Vol. 131, pp. 3-13. https://doi.org/10.1016/j.proeng.2015.12.342

Byrne, G., Dimitrov, D., Monostori, L., Teti, R., van Houten, F. and Wertheim, R. (2018), "Biologicalisation: Biological transformation in manufacturing," CIRP Journal of Manufacturing Science and Technology, Vol. 21, pp. 1-32. https://doi.org/10.1016/j.cirpj.2018.03.003

Ceschin, F., and Gaziulusoy, I. (2016), "Evolution of design for sustainability: From product design to design for system innovations and transitions", Design studies, Vol. 47, pp.118-163. https://doi.org/10.1016/ j.destud.2016.09.002

Cohen, Y. H. and Reich, Y. (2016), Biomimetic Design Method for Innovation and Sustainability, Springer, Cham.

Dias-Ferreira, J., Ribeiro, L., Akillioglu, H., Neves, P., and Onori, M. (2018), "BIOSOARM: a bio-inspired selforganising architecture for manufacturing cyber-physical shopfloors", Journal of Intelligent Manufacturing, Vol. 29 No. 7, pp. 1659-1682. https://doi.org/10.1007/s10845-016-1258-2

Dias-Ferreira, J., Ribeiro, L., Akillioglu, H., Neves, P., and Onori, M. (2018), "BIOSOARM: a bio-inspired selforganising architecture for manufacturing cyber-physical shopfloors", Journal of Intelligent Manufacturing, Vol. 29 No. 7, pp. 1659-1682.

Domke, M. L., and Hashemi Farzaneh, H. (2018), "Research in bio-inspired design-what is its current focus?", In DS 89: Proceedings of The Fifth International Conference on Design Creativity (ICDC 2018), University of Bath, Bath, UK, January 31st - February 2nd 2018, pp. 314-321.

Drossel, W., Dani, I., and Wertheim, R. (2019), "Biological transformation and technologies used for manufacturing of multifunctional metal-based parts", Procedia Manufacturing, Vol. 33, pp. 115-122. https://doi.org/10.1016/j.promfg.2019.04.016 
du Plessis, A., Broeckhoven, C., Yadroitsava, I., Yadroitsev, I., Hands, C. H., Kunju, R., and Bhate, D. (2019), "Beautiful and functional: a review of biomimetic design in additive manufacturing", Additive Manufacturing, Vol. 27, pp. 408-427. https://doi.org/10.1016/j.addma.2019.03.033

Esat, R., and Ahmed-Kristensen, S. (2018), "Classification of bio-design applications: towards a design methodology", In DS 92: Proceedings of the DESIGN 2018 15th International Design Conference, pp. 1031-1042. https://doi.org/10.21278/idc.2018.0531

Faludi, J., Ali, O., Srour, O., Mecanna, S., Kamareddine, R., and Chatty, T. (2019), "Preliminary Results Testing What Different Design Solutions Arise from Different Sustainable Design Methods", In Proceedings of the Design Society: International Conference on Engineering Design, July 2019, Cambridge University Press, Vol. 1, No. 1, pp. 3351-3360. https://doi.org/10.1017/dsi.2019.342

Fayemi, P. E., Wanieck, K., Zollfrank, C., Maranzana, N., and Aoussat, A. (2017), "Biomimetics: process, tools and practice", Bioinspiration \& biomimetics, Vol. 12 No. 1, pp. 011002.

Fu, K., Moreno, D., Yang, M., and Wood, K. L. (2014), "Bio-inspired design: an overview investigating open questions from the broader field of design-by-analogy”, Journal of Mechanical Design, Vol. 136 No. 11. https://doi.org/10.1115/1.4028289

Goel, A., Rugaber, S., and Vattam, S. (2009), "Structure, behavior \& function of complex systems: The SBF modeling language", International Journal of AI in Engineering Design, Analysis and Manufacturing, Vol. 23 No. 1, pp. 23-35. https://doi.org/10.1017/S0890060409000080

Graeff, E., Maranzana, N., and Aoussat, A. (2019), "Biomimetics, where are the biologists?", Journal of Engineering Design, Vol. 30 No. 8-9, pp. 289-310. https://doi.org/10.1080/09544828.2019.1642462

Hashemi Farzaneh, H. (2020), "Bio-inspired design: the impact of collaboration between engineers and biologists on analogical transfer and ideation”, Research in Engineering Design, Vol. 31 No. 3, pp. 299322. https://doi.org/10.1007/s00163-020-00333-w

Hashemi Farzaneh, H., Angele, F., and Zimmermann, M. (2019), "Bio-Inspired Design for Additive Manufacturing-Case Study: Microtiter Plate”, In Proceedings of the Design Society: International Conference on Engineering Design, July 2019, Cambridge University Press, Vol. 1 No. 1, pp. 289-298. https://doi.org/10.1017/dsi.2019.32

Helms, M., Vattam, S. S., and Goel, A. K. (2009), "Biologically inspired design: process and products", Design studies, Vol. 30 No. 5, pp. 606-622. https://doi.org/10.1016/j.destud.2009.04.003

Hill, B. (2005), "Goal Setting Through Contradiction Analysis in the Bionics-Oriented Construction Process", Creativity and Innovation Management, Vol. 14 No. 1, pp. 59-65. https://doi.org/10.1111/j.14768691.2005.00325.x

Jia, Z., Yu, Y., and Wang, L. (2019), "Learning from nature: Use material architecture to break the performance tradeoffs", Materials \& Design, Vol. 168, pp. 107650. https://doi.org/10.1016/j.matdes.2019.107650

Kaiser, M. K., Hashemi, F. H., and Lindemann, U. (2014), "Bioscrabble-the role of different types of search terms when searching for biological inspiration in biological research articles", In DS 77: Proceedings of the DESIGN 2014 13th International Design Conference, pp. 241-250.

Lenau, T. A., Keshwani, S., Chakrabarti, A., and Ahmed-Kristensen, S. (2015), "Biocards and level of abstraction”, In: 20th International Conference on Engineering Design (ICED), July 27-31 2015, Milan, Italy, pp. 177-186.

Lenau, T., Dentel, A., Ingvarsdóttir, P., and Guđlaugsson, T. (2010), "Engineering design of an adaptive leg prosthesis using biological principles", In DS 60: Proceedings of DESIGN 2010, the 11th International Design Conference, Dubrovnik, Croatia, May 17 - 20 2010, Design Society, Glasgow, pp.331-340.

Letard, A., Graeff, E., Maranzana, N., Raskin, K., and Aoussat, A. (2020), "How do designers impact the biometric concepts typology?", In DS 104: Proceedings of the 22nd International Conference on Engineering and Product Design Education (E\&PDE 2020), VIA Design, VIA University in Herning, Denmark. 10th -11th September 2020. https://doi.org/10.35199/EPDE.2020.33

Li, S., Bai, H., Shepherd, R. F., and Zhao, H. (2019), "Bio-inspired Design and Additive Manufacturing of Soft Materials, Machines, Robots, and Haptic Interfaces", Angewandte Chemie International Edition, Vol. 58 No. 33, pp. 11182-11204. https://doi.org/10.1002/anie.201813402

Machado, C. G., Winroth, M. P., and Ribeiro da Silva, E. H. D. (2020), "Sustainable manufacturing in Industry 4.0: an emerging research agenda", International Journal of Production Research, Vol. 58 No. 5, pp. 14621484. https://doi.org/10.1080/00207543.2019.1652777

Miehe, R., Bauernhansl, T., Beckett, M., Brecher, C., Demmer, A., Drossel, W. G., ... and Horbelt, J. (2020), "The biological transformation of industrial manufacturing-Technologies, status and scenarios for a sustainable future of the German manufacturing industry”, Journal of Manufacturing Systems, Vol. 54, pp.50-61. https://doi.org/10.1016/j.jmsy.2019.11.006

Miehe, R., Bauernhansl, T., Schwarz, O., Traube, A., Lorenzoni, A., Waltersmann, L., Full, J., Horbelt, J., and Sauer, A. (2018), "The biological transformation of the manufacturing industry-envisioning biointelligent value adding”, Procedia CIRP, Vol. 72, pp. 739-743. https://doi.org/10.1016/j.procir.2018.04.085

Miehe, R., Full, J., Scholz, P., Demmer, A., Bauernhansl, T., Sauer, A., and Schuh, G. (2019), “The Biological Transformation of Industrial Manufacturing - Future Fields of Action in Bioinspired and Bio-based 
Production Technologies and Organization," in 25th International Conference on Production Research Manufacturing Innovation: Cyber Physical Manufacturing, Chicago, Illinois (USA), August 9-14, Procedia Manufacturing, Vol. 39, pp. 737-744.

Neugebauer, R., Ihlenfeldt, S., Schließmann, U., Hellmich, A., and Noack, M. (2019), “A new generation of production with cyber-physical systems-enabling the biological transformation in manufacturing", Journal of Machine Engineering, Vol. 19 No. 1, pp. 5-15. https://doi.org/10.5604/01.3001.0013.0440

Pereira, P.M.M., Monteiro, G.A. and Prazeres, D.M.F. (2015), "General Aspects of Biomimetic Materials", in Pacheco Torgal, F., Labrincha, J.A., Diamanti, M.V., Yu, C.-P. and Lee, H.K. (Eds.), Biotechnologies and Biomimetics for Civil Engineering, Springer International Publishing, Cham, pp. 57-79. https://doi.org/10. 1007/978-3-319-09287-4_3

San Ha, N., and Lu, G. (2020), "A review of recent research on bio-inspired structures and materials for energy absorption applications”, Composites Part B: Engineering, Vol. 181, pp.107496. https://doi.org/10.1016/ j.compositesb.2019.107496

Sartori J, Pal U, Chakrabarti, A. (2010), “A methodology for supporting "transfer" in biomimetic design", Artificial Intelligence for Engineering Design, Analysis and Manufacturing, Vol. 24 No. 4, pp. 483-505.

Sayuti, A., and Ahmed-Kristensen, S. (2020), "Understanding emotional responses and perception within new creative practices of biological materials", In Proceedings of the Sixth International Conference on Design Creativity (ICDC 2020), pp. 144-151. https://doi.org/10.35199/ICDC.2020.18

Sharma, S., and Sarkar, P. (2019), "Biomimicry: Exploring research, challenges, gaps, and tools", In Chakrabarti A. (ed), Research into design for a connected world, Springer, Singapore, Vol. 134, pp. 87- 97. https://doi.org/10.1007/978-981-13-5974-3_8

Svendsen, N., and Lenau, T. A. (2019), "How does biologically inspired design cope with multi-functionality?", In Proceedings of the Design Society: International Conference on Engineering Design, Cambridge University Press, Vol. 1 No. 1, pp. 349-358. https://doi.org/10.1017/dsi.2019.38

Thompson, M. K., Moroni, G., Vaneker, T., Fadel, G., Campbell, R. I., Gibson, I., ... and Martina, F. (2016), "Design for Additive Manufacturing: Trends, opportunities, considerations, and constraints", CIRP annals, Vol. 65 No. 2, pp. 737-760. https://doi.org/10.1016/j.cirp.2016.05.004

Ueda, K. (1992), “A concept for bionic manufacturing systems based on DNA-type information”, In Human Aspects in Computer Integrated Manufacturing, pp. 853-863. https://doi.org/10.1016/B978-0-444-894656.50078-8

Vaneker, T., Bernard, A., Moroni, G., Gibson, I., and Zhang, Y. (2020), "Design for additive manufacturing: Framework and methodology", CIRP Annals, Vol. 69 No.2, pp. 578-599. https://doi.org/10.1016/ j.cirp.2020.05.006

VDI 6220 (2012), Biomimetics - Conception and Strategy, Beuth, Berlin

Voelkl, H., and Wartzack, S. (2018), "Design for composites: tailor-made, bio-inspired topology optimization for fiber-reinforced plastics”, In DS 92: Proceedings of the DESIGN 2018 15th International Design Conference, pp. 499-510. https://doi.org/10.21278/idc.2018.0126

Wegener, K., Gittler, T., and Weiss, L. (2018), "Dawn of new machining concepts: Compensated, intelligent, bioinspired”, Procedia CIRP, Vol.77, pp. 1-17. https://doi.org/10.1016/j.procir.2018.08.194

Weidner, B. V., Nagel, J., and Weber, H. J. (2018), "Facilitation method for the translation of biological systems to technical design solutions", International Journal of Design Creativity and Innovation, Vol. 6 No. 3-4, pp. 211-234. https://doi.org/10.1080/21650349.2018.1428689

Whitesides, G. M. (2015), “Bioinspiration: something for everyone," Interface Focus, Vol. 5 No. 4, pp. 201500312015. https://doi.org/10.1098/rsfs.2015.0031

Willocx, M., Ayali, A., and Duflou, J. R. (2020), "Where and how to find bio-inspiration?: A comparison of search approaches for bio-inspired design”, CIRP Journal of Manufacturing Science and Technology, Vol. 31, pp. 61-67. https://doi.org/10.1016/j.cirpj.2020.09.013

Yargin, G. T., Firth, R. M., and Crilly, N. (2018). "User requirements for analogical design support tools: Learning from practitioners of bio-inspired design”, Design Studies, Vol. 58, pp. 1-35. https://doi.org/10.1016/j.destud.2017.11.006

Yen J, Helms M, Goel A, Tovey C, Weissburg M (2014), “Adaptive evolution of teaching practices in biologically inspired design”, In: Goel AK, McAdams DA, Stone RB (eds) Biologically inspired design - computational methods and tools, Springer, London, pp. 153-199. https://doi.org/10.1007/978-1-4471-5248-4_7

Zhang, Y., Wang, Z., Zhang, Y., Gomes, S., and Bernard, A. (2020), "Bio-inspired generative design for support structure generation and optimization in Additive Manufacturing (AM)", CIRP Annals, Vol. 69 No.1, pp. 117-120. https://doi.org/10.1016/j.cirp.2020.04.091 